\title{
SARS-CoV-2 Modelo de Inoculación en la Cavidad Oral. Revisión de la Literatura
}

\author{
SARS-CoV-2 Model of Inoculation in the Oral Cavity. Literature Review
}

Villanueva- Sánchez, Francisco Germán \& Escalante-Macías, Lilia Haidé

\begin{abstract}
VILLANUEVA-SÁNCHEZ, F. G. \& ESCALANTE-MACÍAS, L. H. SARS-CoV-2 modelo de inoculación en la cavidad oral. Revisión de la literatura. Int. J. Odontostomat., 14(4):495-500, 2020.

RESUMEN: El virus SARS-CoV-2 ingresa al organismo de un individuo susceptible a través de la cavidad oral, nasal o de la mucosa conjuntival; busca ensamblarse por medio de su glicoproteína de superficie o espiga con los receptores de la enzima convertidora de angiotensina 2 que en boca los encontramos con mayor expresión en las células escamosas que recubren el epitelio lingual y las glándulas salivales, una vez que ingresa por medio de la activación de proteasas ingresa a la célula huésped para denudar su RNA viral, a diferencia de otros virus no necesita ir hasta el núcleo de tal forma que en el citoplasma inicia su replicación y utiliza los ribosomas del huésped para formar una gran cantidad de proteínas virales tanto estructurales como accesorias que le permita formar nuevos viriones potencialmente infecciosos; los estomatólogos deben tomar en cuenta esta vía de infección y extremar las medidas para disminuir su carga viral local en la cavidad oral y las barreras físicas de protección para el operador, el paciente y la ergonomía del consultorio.
\end{abstract}

PALABRAS CLAVE: SARS-CoV-2, inoculación, cavidad oral, glándulas salivales.

\section{INTRODUCCIÓN}

COVID-19 o SARS-CoV-2 es un virus de esférico pleomórfico que contiene una cadena de RNA simple o monocatenario asociado a una nucleoproteína, así como una cápside con una matriz proteica; está presenta proyecciones en forma de espiga en su superficie, así como hemaglutinin-esterasa. La vía e inoculación oral se da mediante gotas de saliva y aerosoles producidos por un paciente infectado y la aspiración del huésped, una vez localizado sobre el epitelio escamoso estratificado de la lengua y el epitelio glandular el virus busca a los receptores ECA2 (receptores de enzima convertidora de angiotensina 2) en unión con una proteasa llamada TMPRSS2 permiten la entrada del virus al interior de la célula huésped y posteriormente el RNA viral utiliza los ribosomas de la misma para iniciar la transcripción del RNA viral y permitir la replicación viral; dos de los sitios con mayor cantidad de receptores ECA2 son las glándulas y el epitelio escamoso estratificado de la mucosa de la lengua lo que les confiere ser un reservorio del virus que le permite una replicación adecuada y aumento de su carga viral; por lo tanto es potencialmente infec- cioso en las funciones masticatorias, deglución, habla, respiración y demás del tracto aéreo superior. Por lo tanto, la saliva parece ser un medio de detección más seguro que los que en la actualidad existen y el estomatólogo deberá poner principal atención en esta vía de inoculación al formar parte su campo anatómico de acción (Mousavizadeh \& Ghasemi, 2020; Chen et al., 2020).

Estructura genómica y ciclo viral: SARS-CoV-2 es un virus esférico pleomórfico que contiene una cadena de RNA monocatenario que va en sentido positivo asociado a una nucleoproteína protegido por una cápside con matriz proteica; en su superficie presenta una glicoproteína que tiene forma de espiga (Fig. 1) y que sirve de receptor de unión; así mismo presenta otras proteínas como la hemaglutinin-esterasa (HE). La familia de coronavirus pose genomas largos que van desde 26,4 a $31,7 \mathrm{~kb}$ (kilo bases) entre todos los virus conocidos de RNA presentan variaciones en los aminoácidos Guanina + Citocina $(G+C)$ entre un 32 a $43 \%$ ( Mousavizadeh \& Ghasemi). 
Dentro del árbol filogenético pertenece a los Beta coronavirus, para que el virus ingrese a las células del huésped se une a los receptores de ECA2 mediante la glicoproteína de superficie en forma de espiga fungiendo como llave, para que el virus complete la entrada después del proceso inicial la glicoproteína de espiga debe ser activada por una proteasa llamada TMPRSS2. Una vez dentro de la célula huésped el genoma se transcribe y luego se traduce, la replicación y transcripción se lleva acabo en las membranas citoplasmáticas e implican procesos coordinados de síntesis de RNA continua y discontinua que son mediados por la replicación viral, un complejo proteico grande de replicación de $20 \mathrm{~kb}$ (Mousavizadeh \& Ghasemi; Chen et al.).

Se tiene evidencia que el complejo de replicación se compone por 16 proteínas no estructurales, así como por cuatro proteínas estructurales la de espiga en la cubierta de la cápside, envoltura, membrana y nucleocápside que se encuentra de manera interna protegiendo el RNA viral, así como algunas esterasas como la hemaglutinin-esterasa (Mousavizadeh \& Ghasemi).

Es importante mencionar la actividad de las RNA polimerasa, RNA helicasa y proteasas dependientes de RNA que son comunes en este tipo de virus. De igual manera se ha observado que la replicasa de coronavirus emplea una variedad de enzimas de procesamiento de RNA viral que no se han encontrado en este tipo de virus como una secuencia putativa de endo-ribonucleasa específica, de 3'a 5' exo-ribonucleasas, 2'O ribosa metiltransferasa, ADP ribosa, 1 'fosfatasa, así como la actividad de ciclos de fosfodiesterasa. Una vez elaboradas las proteínas por los ribosomas de la célula huésped se ensamblan en la membrana celular y se incorpora RNA genómico a medida que las partículas maduras se forman por exocitosis traspasan las membranas celulares internas (Chen et al.).

\section{Sistema renina angiotensina aldosterona (SRAA)}

Los principales componentes que forman el sistema son la renina, el angiotensinógeno, la enzima convertidora de angiotensina 1 ECA 1 , la enzima convertidora de angiotensina 2 ECA 2 y los receptores de siete dominios transmembranales AT1 y AT2. La renina es una aspartil proteasa que se sintetiza y almacena en el aparato yuxtaglomerular en las nefronas renales aquí se cataliza la liberación hidrolítica del decapéptido llamado angiotensina I, a partir del angiotensinógeno de 14 aminoácidos que es sintetizado en el hígado. Posterior a este proceso la angiotensina I es convertida en octapéptido angiotensina II por la ECA (Ames, 2019).

La angiotensina II tiene una vida media de 15 a 60 segundos y constituye el producto final con mayor actividad biológica del SRAA. Está actúa en el músculo liso vascular, aumenta la presión sanguínea más que cualquier neurotransmisor como la noradrenalina. Actúa también en la zona glomerular de la corteza suprarrenal estimulando la síntesis y secreción de aldosterona en el túbuloproximal este proceso incrementa de manera importante la resorción de sodio e inhibe la secreción de renina, a nivel de sistema nervioso estimula la ingestión de agua y aumenta la secreción de vasopresina (Ames et al., 2019).

La degradación de la angiotensina II por aminopeptidasas lleva a la formación de angiotensina III y IV de las cuales se tiene poco conocimiento en cuanto a su actividad biológica y degradación (Ames et al.).

\section{Receptores membranales de angiotensina II}

Actualmente se considera que las múltiples actividades biológicas de la angiotensina II, tanto a nivel circulatorio y a nivel de los tejidos son mediadas por dos subtipos principales de receptores: AT1 y AT2. En humanos el receptor AT1 es codificado por un gen localizado en el brazo largo, locus 22 del cromosoma 3. Es el tipo más predominante en los adultos se caracteriza por acoplarse a diferentes proteínas $\mathrm{Ga}$ mismas que les permiten activar fosfolipasas A, D y C que generan inositol 1, 4, 5trifosfato y diacilglicerol una molécula que activa a la proteína cinasa, esta a su vez fosforila diferentes proteínas que participan en la contracción del músculo liso y secreción de aldosterona, así como el crecimiento y proliferación celular. De esta manera este receptor lleva acabo la mayoría de las funciones conocidas de la angiotensina II como la vasoconstricción, el incremento de la proliferación celular y aumento en la contractilidad cardiaca (Koka et al., 2008).

Mientras que el gen que codifica al receptor AT2 se encuentra en el cromosoma $X$, este se expresa de manera predominante durante el periodo fetal disminuyendo considerablemente hacia el nacimiento. Sin embargo, los niveles de expresión de 
este receptor se incrementan bajo condiciones de estrés y daño tisular. Sus vías de señalización aun no son del todo conocidas, pero se ha evidenciado que antagoniza las acciones del receptor AT1, propiciando la vasodilatación, regula apoptosis, intervienen en desarrollo feta, aumenta la producción de óxido nítrico y la diferenciación tisular (Ames et al.; Koka et al.).

El hígado es el sitio anatómico más importante de expresión del gen del angiotensinógeno, sin embargo, el RNAm del mismo se expresa en diferentes tejidos extrahepáticos, incluidos el cerebro, grandes vasos y arterias, riñón, corazón, tejido adiposo y recientemente encontrados en glándulas salivas y mucosas del tracto aéreo superior como el epitelio escamoso estratificado de la lengua (Ames et al.).

La ECA estructuralmente es una metalopeptidasa de zinc y funcionalmente una ectoenzima unida a membrana que representa el paso enzimático final en la producción de angiotensina II a partir de angiotensina I; existen tres isoformas principales ECA somática, ECA testicular o germinal y ECA plasmática o soluble (Ames et al.).

\section{Glándulas salivales}

Las glándulas salivales forman parte del complejo sistema digestivo, son órganos accesorios cuya función principal es la secreción salival como respuesta a un estimulo físico o psíquico. De a cuerdo a su clasificación se pueden dividir en extramurales o glándulas mayores integradas por parótida, submandibulares y sublinguales e intramurales o glándulas menores localizadas en la mucosa y submucosa de la cavidad oral (de Paulaet al., 2017).
Histológicamente consisten en unidades morfofuncionales secretoras conectadas a la cavidad oral a través de un sistema de conductos; están conformadas por células serosas y mucosas organizadas morfofuncionalmente en estructuras acinares, elongadas o tubulares cuyo objetivo principal es la producción salival; estas glándulas salivales mayores son órganos pares secretan y excretan el $97 \%$ de la saliva total que permea hacia la cavidad oral (de Paula et al., 2017).

Dentro de las principales funciones de la saliva esta: mantener la lubricación y humedad fisiológica del tracto oral-faríngeo- esofágico, mantener el equilibrio de la microflora oral, coadyuvar en el funcionamiento de la precepción del sentido del gusto e identificación de sabores, participar en la disolución, suspensión, conformación y deglución del bolo alimenticio, iniciar el proceso de la digestión, mantener la integridad de la mucosa oral, realizar funciones de solución biológica amortiguadora, remineralización de los órganos dentarios así como todas las funciones de inmunidad como primera barrera de defensa de esta cavidad (de Paula et al.; Cutler \& Gremski, 1991).

Recordando su morfogénesis se originan de la invaginación y proliferación de células epiteliales del ectodermo en el tejido mesénquima subyacente hacia la sexta y séptima semana de vida intrauterina. De esta manera las células epiteliales constituyen los acinos y los conductos que conformarán el epitelio glandular del parénquima mientras que el tejido conectivo les dará soporte a estas unidades morfofuncionales (Cutler \& Gremski)

En la siguiente tabla se resumen algunas de las características de las glándulas salivales mayores:

Tabla I. Funciones específicas de las glándulas salivales mayores.

\begin{tabular}{|c|c|c|c|}
\hline \multicolumn{4}{|c|}{ Glándulas Salivales Mayores } \\
\hline Características & Parótidas & Submandibulares & Sublinguales \\
\hline Mecanismo de secreción & Merocrino & Merocrino & Merocrino \\
\hline Tipo de secreción & Serosa & Mixta (seromucosa) & Mixta (mucoserosa) \\
\hline Células epiteliales & Acinares serosas & $\begin{array}{c}\text { Acinares serosas, mucosas } \\
\text { y mixtas }\end{array}$ & $\begin{array}{c}\text { Acinares mucosas, serosas } \\
\text { mixtas }\end{array}$ \\
\hline $\begin{array}{c}\text { Conductos porción } \\
\text { excretora }\end{array}$ & $\begin{array}{c}\text { Intercalares largos } \\
\text { Estriados bien } \\
\text { desarrollados } \\
\text { Excretores extralobulillares }\end{array}$ & $\begin{array}{c}\text { Intercalares cortos } \\
\text { Estriados largos } \\
\text { Excretores extralobulillares }\end{array}$ & $\begin{array}{c}\text { Intercalares poco } \\
\text { desarrollados } \\
\text { Estriados cortos } \\
\text { Excretores extralobulillares }\end{array}$ \\
\hline Otras características & $\begin{array}{l}\text { Abundantes adipocitos } \\
\text { aumentan con el } \\
\text { envejecimiento }\end{array}$ & $\begin{array}{l}\text { Menor cantidad de } \\
\text { adipocitos }\end{array}$ & Ausencia de adipocitos \\
\hline
\end{tabular}




\section{Expresión génica de receptores ECA2}

Existe evidencia científica que reporta expresión génica de los receptores de la enzima convertidora de angiotensina AT1 y AT2 en la cavidad oral específicamente en las células epiteliales que recubren la lengua y las glándulas salivales. Reportan secuenciación completa de transcriptoma de muestras de 695 tejidos provenientes de diferentes órganos, correspondientes a: 51 de intestino, 129 de riñón, 35 de estómago, 9 de conducto biliar, 50 de hígado, 32 de la cavidad oral, 110 de pulmón, 59 de tiroides, 11 de esófago, 19 de vejiga, 113 mama, 25 de útero, 52 de próstata (Xu et al., 2020a).

En primera instancia realizaron la cuantificación de la expresión génica por órganos presentándose en mayor cantidad en: intestino delgado, testículos, tejido adiposo, glándula tiroides, riñón, musculo cardiaco, colón, mama, ovario, glándulas salivales y lengua entre otros. Al realizar la evaluación de los casos de la cavidad oral se identifico una mayor expresión génica en las células escamosas de la mucosa de la lengua seguidas por la mucosa del piso de boca, base de la lengua y glándulas salivales. Así mismo al realizar la evaluación de expresión por células individuales se pudo determinar que las que presentan más expresión son las células epiteliales seguidas por las células $T$, fibroblastos, linfocitos $B$, células endoteliales y mastocitos (Xu et al., 2020a).

Todo este análisis de secuenciación masiva nos permite inferir que el SARS-CoV-2 no afecta de manera exclusiva a los receptores de pulmón si no por el contrario hace una inoculación de viriones en todos los órganos y sitio antes mencionados. Esto le confiere al paciente que sufre la infección una falla multiorgánica que en algunos casos tiene como desenlace la muerte (Xu et al., 2020a).

\section{Inoculación de la cavidad oral}

En lo que respecta a la inoculación del virus en la cavidad oral y su potencial como reservorio de SARS-CoV-2, una vez que el virus entra en contacto con las células epiteliales de la cavidad oral en un individuo susceptible por medio de la aspiración de microgotas, aerosoles, fómites o excretas; el virus buscará el receptor de la enzima convertidora de angiotensina 2 para que se una a su receptor correspondiente en este caso la glicoproteína de superficie o proteína espiga, una vez realizado el ensamblaje de ambos receptores serán activados por la proteasa
TMPRSS2 para darle ingreso a ese virión a la célula huésped (Chen et al., 2020).

Una vez dentro de la célula el virus inteligente se desnuda eliminando su cápside y nucleoproteínas de protección, para dejar el RNA viral libre en el citoplasma, a diferencia de otros virus el SARS-CoV-2 no necesita viajar hasta el núcleo para insertar su secuencia viral por el contrario utiliza al ribosoma para iniciar su replicación, transcripción y traducción de proteínas virales tanto estructurales como accesorias esto le permitirá formar una nueva vesícula que conformara un nuevo virión, una vez conformado saldrá de la célula huésped por exocitosis listo para infectar más órganos $u$ otros individuos hasta conformar un número importante de copias virales que le conferirá una carga viral potencialmente infecciosa (Chen et al.) (Fig. 1).

En este sentido es importante hacer énfasis en los profesionales de la estomatología en que la capacidad de estas gotas con viriones para infectar otros individuos dependerá del tamaño de la partícula se sabe que gotas mayores a $60 \mathrm{~mm}$ por su constitución y peso caen hacia el piso, gotas menores a $60 \mathrm{~mm}$ pueden tener una transmisión de corto alcance y menores a $10 \mathrm{~mm}$ rompen su núcleo y se suspenden en aerosoles involucrando transmisión a larga distancia. Se tiene evidencia de que un estornudo puede generar 3000 núcleos de gotas de saliva, mismos que son equivalentes a los que se expele en una conversación de 5 minutos entre dos individuos, por otro lado, el estornudo puede generar alrededor de 40,000 núcleos (Xu et al., 2020b).

La viabilidad de estas gotas se determina en función del tamaño de su núcleo, la descomposición biológica dependerá del flujo de aire, deshidratación es decir del clima de la exposición a rayos ultravioleta, así como a otros agentes químicos bien conocidos como el hipoclorito de sodio al 0,1\%, etanol entre el 60 y $70 \%$ y el peróxido de hidrógeno (Xu et al., 2020b; Sri Santosh et al., 2020).

\section{Consideraciones en la practica estomatológica}

Como personal de salud en la practica estomatológica debemos de tener la consideración de que el SARS-CoV-2 utiliza la cavidad oral y faringe como puerta de entrada, una vez revisada la evidencia científica se puede considerar como un reservorio del virus que se encuentra en constante replicación con la finalidad de formar cada vez más copias virales 


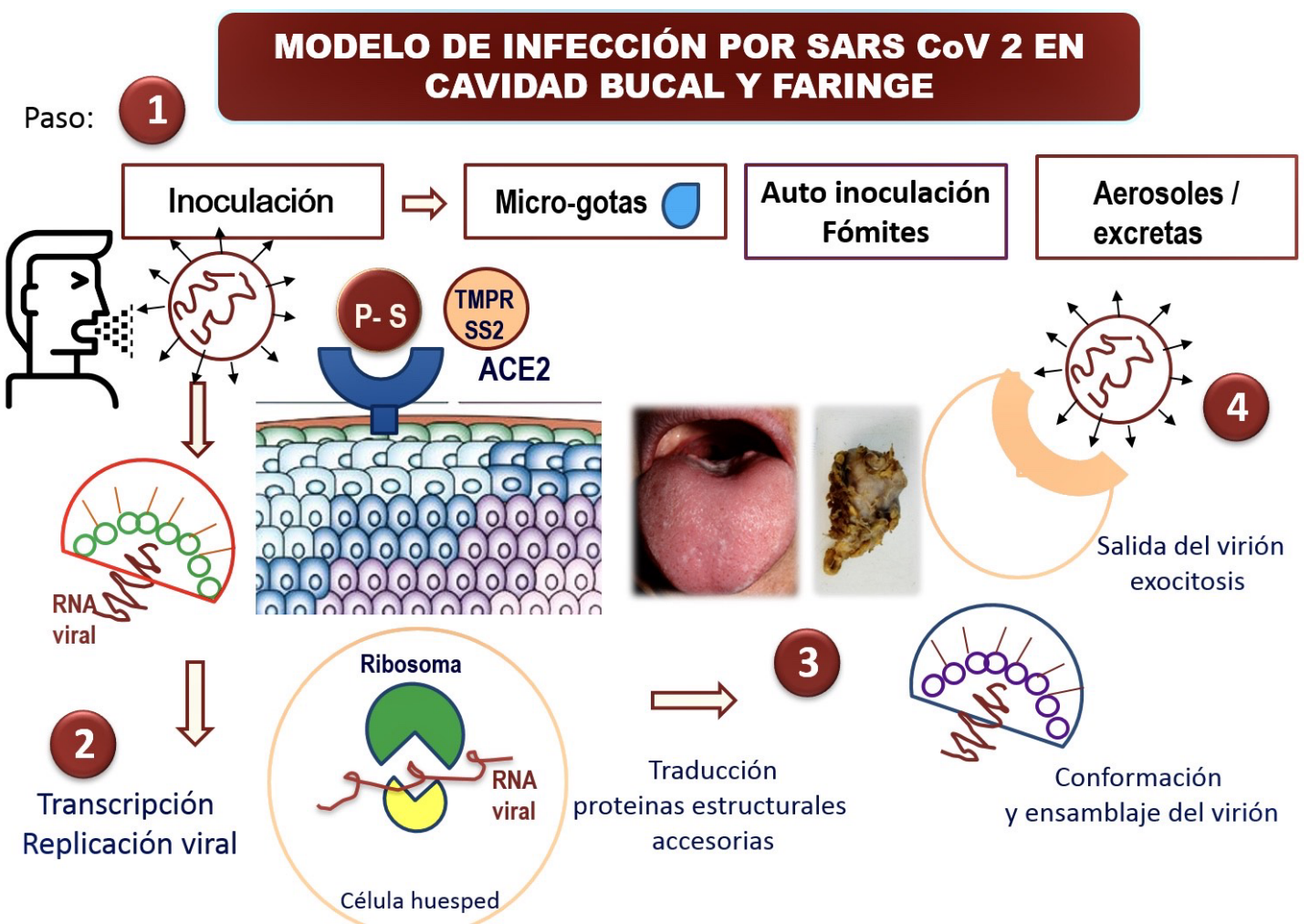

Elaborado: Dr. Germán Villanueva S.

Fig. 1. Modelo de inoculación viral en cavidad oral, mediante receptores de enzima convertidora de angiotensina 2 en las células escamosas de la lengua y las glándulas salivales.

aumentado su carga viral, esta es potencialmente infecciosa y se puede diseminar hacia otros órganos y tejidos del cuerpo, pero así mismo las glándulas pueden expeler una cantidad importante de viriones en estas microgotas de saliva que aunado a los métodos odontológicos como la pieza de mano de alta velocidad potencia de una manera muy importante la generación de aerosoles con suspensión de partículas virales potencialmente infecciosas. Estas pueden quedar distribuidas en todo el consultorio en superficies, unidad dental, aparato de rayos x y demás fómites y por supuesto en el operador (Agalar \& Öztürk Engin, 2020; Malhotra et al., 2020).

De esta manera se debe de considera que si estos reservorios están en constante replicación, transcripción y traducción de proteínas virales tanto estructurales como accesorias, un método local para disminuir esta carga viral antes de empezar a realizar manipulación de la cavidad oral por mínima invasión, es recomendable que el paciente pueda realizar colutorios con yodopovidona oral y peróxido de hidrogeno para disminuir de manera considerable la carga viral local de la mucosa oral y el parénquima glandular. Así mismo extremar las barreras de protección física universales que consideran al operador incluye: 1) colocación de overol manga larga y gorro, 2) bata quirúrgica desechable sobre el overol, 3) colocación de gorro y botas quirúrgicas desechables sobre gorro de overol y zapatos, 4) colocación de cubrebocas sobre N95, 5) lentes y careta, 6) dos pares de guantes de preferencia de nitrilo. Así mismo campo para el paciente y a los implementos ergonómicos del consultorio dental. Posterior a la consulta el protocolo de desinfección de superficies, ventilación y lavado, así como esterilización continua del instrumental en autoclave (Agalar \& Öztürk Engin; Malhotra et al.).

VILLANUEVA- SÁNCHEZ, F. G. \& ESCALANTE-MACÍAS, L. H. SARS-CoV-2 model of inoculation in the oral cavity. Literature review.. Int. J. Odontostomat., 14(4):495-500, 2020.

ABSTRACT: SARS-CoV-2 virus enters the body of a susceptible individual through oral, nasal or conjunctival mucosa, seeking to bind to the spike glycoprotein surface 
through angiotensin-converting enzyme 2 receptors. These are found in the mouth with a higher expression in oral squamous cells that cover the lingual epithelium and salivary glands. Once proteolytic activation begins, it enters the host cell to denudate its viral RNA. In contrast with other viruses, it does not require nucleus access, and therefore replicates in the cytoplasm using the host's ribosomes to produce great amounts of both structural and accessory viral proteins. Since this generates new and potentially infectious virions, dentists must consider this route of infection and take extreme measures to decrease their viral load in the oral cavity. Physical protection barriers for the operator, the patient and the health and safety of the work place are critical in these cases.

KEY WORDS: SARS-CoV-2, inoculation, oral cavity, salivary glands.

\section{REFERENCIAS BIBLIOGRÁFICAS}

Agalar, C. \& Öztürk Engin, D. Protective measures for COVID-19 for healthcare providers and laboratory personnel. Turk. J. Med. Sci., 50(SI-1):578-84, 2020.

Ames, M. K.; Atkins, C. E. \& Pitt, B. The renin-angiotensinaldosterone system and its suppression. J. Vet. Intern. Med., 33(2):363-82, 2019.

Chen, Y.; Liu, Q. \& Guo, D. Emerging coronaviruses: genome structure, replication, and pathogenesis. J. Med. Virol., 92(4):418$23,2020$.

Cutler, L. S. \& Gremski, W. Epithelial-mesenchymal interactions in the development of salivary glands. Crit. Rev. Oral Biol. Med., 2(1):1-12, 1991.

de Paula, F.; Teshima, T. H. N.; Hsieh, R.; Souza, M. M.; Nico, M. M. S. \& Lourenco, S. V. Overview of human salivary glands: highlights of morphology and developing processes. Anat. Rec. (Hoboken), 300(7):1180-8, 2017.

Koka, V.; Huang, X. R.; Chung, A. C. K.; Wang, W.; Truong, L. D. \& Lan, H. Y. Angiotensin II up-regulates Angiotensin I-Converting Enzyme (ACE), but down-regulates ACE2 via the AT1-ERK/p38 MAP kinase pathway. Am. J. Pathol., 172(5):1174-83, 2008.

Malhotra, N.; Gupta, N.; Ish, S. \& Ish, P. COVID-19 in intensive care. Some necessary steps for health care workers. Monaldi Arch. Chest. Dis., 90(1), 2020. DOI: https://www.doi.org/10.4081/ monaldi.2020.1284

Mousavizadeh, L. \& Ghasemi, S. Genotype and phenotype of COVID-19: Their roles in pathogenesis. J. Microbiol. Immunol. Infect., 2020. DOI: https://www.doi.org/10.1016/j.jmii.2020.03.022

Sri Santosh, T.; Parmar, R.; Anand, H.; Srikanth, K. \& Saritha, M. A review of salivary diagnostics and its potential implication in detection of Covid-19. Cureus, 12(4):e7708, 2020.

Xu, H.; Zhong, L.; Deng, J.; Peng, J.; Dan, H.; Zeng, X.; Li, T. \& Chen, Q. High expression of ACE2 receptor of 2019-nCoV on the epithelial cells of oral mucosa. Int. J. Oral Sci., 12(1):8, 2020a.

Xu, R.; Cui, B.; Duan, X.; Zhang, P.; Zhou, X. \& Yuan, Q. Saliva: potential diagnostic value and transmission of 2019-nCoV. Int. J. Oral Sci., 12(1):11, 2020b.
Dirección para correspondencia:

Dr. Francisco Germán Villanueva Sánchez

Coordinador del Departamento de Patología

Oral y maxilofacial

Escuela Nacional de Estudios Superiores de la UNAM León

BLvd. UNAM N< 2011

MEXICO

Email: drvillanueva.enesunam@gmail.com fgvillanueva@enes.unam.mx

Recibido : 21-05-2020

Aceptado: 25-05-2020 